\title{
Profile of Gut Hormones, Pancreatic Hormones and Pro- inflammatory Cytokines in New Zealand Maori
}

\author{
Aya Cervantes ${ }^{a}$, Ruma G. Singha, Sayali A. Pendharkar ${ }^{\text {a }}$, Sakina H. Bharmal ${ }^{\text {a }}$, \\ Maxim S. Petrova, b
}

\begin{abstract}
Background: Maori, indigenous people of New Zealand, have at least two times higher prevalence of obesity and diabetes in comparison with the general population in the country. Gut and pancreatic hormone profile differences as well as pro-inflammatory milieu may contribute to this disparity. The aim was to investigate the differences in gut hormones, pancreatic hormones and pro-inflammatory cytokines between Maori and non-Maori individuals.
\end{abstract}

Methods: This was a cross-sectional study. Fasting blood samples were collected to measure cholecystokinin, ghrelin, gastric inhibitory peptide, glicentin, glucagon-like peptide-1 and -2, oxyntomodulin, secretin, amylin, C-peptide, glucagon, insulin, pancreatic polypeptide, somatostatin, interleukin- 6 , monocyte chemoattractant protein-1 and tumour necrosis factor- $\alpha$. Binary logistic regression analysis was conducted in one unadjusted and four adjusted statistical models adjusting for patient-, metabolic- and pancreatitis-related factors.

Results: A total of 8 Maori and 85 non-Maori individuals were included. Circulating levels of ghrelin, pancreatic polypeptide and interleukin-6 levels were significantly higher in Maori $(\mathrm{P}=0.005, \mathrm{P}=$ 0.003 and $\mathrm{P}=0.011$, respectively) in both unadjusted and all the four adjusted analyses. Other signaling molecules did not show consistently significant associations with ethnicity.

Conclusion: Profile of gut hormones, pancreatic hormones and proinflammatory cytokines appears to differ between Maori and nonMaori individuals, independent of obesity, diabetes and other covariates. This may go some way to explain the increased propensity to obesity and diabetes in the Maori population.

Keywords: Ghrelin; Pancreatic polypeptide; Interleukin-6; Obesity; Ethnicity

\footnotetext{
Manuscript submitted May 8, 2018, accepted May 28, 2018

aSchool of Medicine, University of Auckland, Auckland, New Zealand ${ }^{b}$ Corresponding Author: Maxim S. Petrov, School of Medicine, University of Auckland, Room 12.085A, Level 12, Auckland City Hospital, Auckland 1023, New Zealand. Email: max.petrov@gmail.com
}

doi: https://doi.org/10.14740/gr1042w

\section{Introduction}

Obesity is classified by the World Health Organisation as an epidemic, with an estimate of over 600 million individuals affected worldwide [1]. Further, New Zealand has the third highest rate of obesity in the world [2]. The condition poses a significant burden on healthcare, and is associated with a plethora of diseases, including metabolic diseases, cardiovascular diseases and cancer. That certain ethnicities, including indigenous populations, are over-represented in obesity and metabolic disease-related statistics is a well-recognized public health issue [3]. In New Zealand, the rate of obesity in Maori adults is double the rate of that in non-Maori individuals [2] and Maori people have poorer health outcomes [4]. Similarly, other indigenous populations around the globe, such as Pima Indians in the USA [5, 6], aboriginal Canadians [7, 8], aboriginal Australians [9] and aboriginal Taiwanese[10], have higher prevalence of obesity and poorer health outcomes compared to the general population. These findings place the health disparities among indigenous populations at the forefront, highlighting the need of better understanding the underlying pathogenetic mechanisms in order to develop potential ethnicity-specific preventative and therapeutic measures.

The gut and the pancreas are crucial players in metabolic processes due to the hormones secreted by these organs that regulate metabolic homeostasis [11]. Alterations in circulating levels of gut and pancreatic hormones can disrupt metabolic homeostasis in several ways and, in particular, result in excess adiposity and glucose derangement [12]. Another factor that contributes to impaired metabolic homeostasis is chronic low-grade inflammation characteristic of obesity and impaired glucose tolerance $[13,14]$. Recent studies show that hormones such as insulin, amylin, pancreatic polypeptide (PP) and ghrelin are significantly associated with pro-inflammatory cytokines namely interleukin-6 (IL-6), monocyte chemoattractant protein-1 (MCP-1) and tumour necrosis factor- $\alpha(\mathrm{TNF} \alpha)$ in patients with impaired metabolic homeostasis $[15,16]$.

Socioeconomic inequality and lifestyle factors explain (to some extent) ethnic health disparity $[17,18]$; however, ethnicity-specific differences in hormone levels are suggested to be a contributing factor as well [19-21]. Altered gut and pancreatic hormone levels may predispose certain ethnic groups to obesity and metabolic disorders. Evidence to date, albeit limited, shows that genetic variation and single nucleotide poly- 
morphisms can contribute to altered circulating levels of gut and pancreatic hormones [22-24]. Findings from the study by Koska et al [20] showed that Pima Indians have increased PP levels. Studies by Harris et al [25] and Karim et al [21] showed that African Americans have altered insulin and C-peptide levels. However, whether New Zealand Maori have a unique hormone and cytokine profile that predisposes them to higher risk of obesity and diabetes has never been investigated.

The aim of this study was to investigate profile of gut hormones, pancreatic hormones and pro-inflammatory cytokines in Maori versus non-Maori individuals.

\section{Patients and Methods}

\section{Study design}

This was a post-hoc analysis of the DORADO study - a crosssectional study of individuals with a history of acute pancreatitis (defined prospectively based on international guidelines [26]). The study protocol was granted ethical approval by the Health and Disability Committee (13/STH/182). The protocol of the study was described in detail elsewhere [27-29]. Ethnicity of participants was self-reported and grouped into Maori and non-Maori. Participants identified as Maori were contacted to confirm Maori lineage by obtaining the ethnicity of all four grandparents.

\section{Sample acquisition, storage and laboratory assays}

Fasting (for at least $8 \mathrm{~h}$ ) venous blood was collected for all participants by a certified phlebotomist at the internationally accredited New Zealand medical laboratory, Lab Plus, at Auckland City Hospital. Appropriate inhibitor (aprotinin or dipeptidyl peptidase IV) was added to each tube, and the blood was centrifuged at $4{ }^{\circ} \mathrm{C}$ for $7.5 \mathrm{~min}$ at $4,000 \mathrm{~g}$. Plasma was separated, aliquoted and stored at $-80{ }^{\circ} \mathrm{C}$ until use. Fasting blood glucose, insulin and glycated haemoglobin A1c (HbA1c) were analyzed at Lab-Plus using enzymatic colourimetric assay ( $\mathrm{F}$. Hoffman-La Roche Ltd), chemiluminescence sandwich immunoassay (Roche Diagnostics NZ Ltd) and boronate affinity chromatography assay (Trinity Biotech, Ireland), respectively. Amylin, C-peptide, gastric inhibitory peptide (GIP), glucagon, PP, peptide YY (PYY), IL-6, MCP-1 and TNF $\alpha$ were measured using MILLIPLEX MAP Human metabolic hormone magnetic bead panel based on the Lumixe xMAP (Luminex) technology. Results were quantified $(\mathrm{ng} / \mathrm{mL})$ based on fluorescent reporter signals recorded by the Luminex xPOTENT software (MILLIPLEX Analyst 5.1). Somatostatin, cholecystokinin, gastrin, glicentin, glucagon-like peptide (GLP)-1, GLP-2, oxyntomodulin and secretin were measured using Merck-Millipore enzyme-linked immunosorbent assay (ELISA) kits. Results were quantified using Rayto Microplate Reader (V-2100C; Santa Fe, Granada, Spain), with absorbance of 405 - $630 \mathrm{~nm}$. All hormones and pro-inflammatory cytokines were reported as $\mathrm{ng} / \mathrm{mL}$, except for glicentin and gastrin, which were reported as $\mathrm{pmol} / \mathrm{mL}$ and $\mathrm{pg} / \mathrm{mL}$ respectively.

\section{Definitions}

Etiology was categorized as alcohol, biliary or other (e.g. hypertriglyceridemia, idiopathic pancreatitis, pancreas divisum). Body mass index (BMI, $\mathrm{kg} / \mathrm{m}^{2}$ ) was determined using a digital scale with stadiometer (Health o meter $^{\circledR}$ Professional, 2013, (C) Pelstar, LLC, IL, USA). Participants were categorized into three groups: 1) healthy $\left.\left(18.5-24.9 \mathrm{~kg} / \mathrm{m}^{2}\right), 2\right)$ overweight $(25$ - $\left.29.9 \mathrm{~kg} / \mathrm{m}^{2}\right)$ and 3$)$ obese $\left(\geq 30.0 \mathrm{~kg} / \mathrm{m}^{2}\right)$ in accordance to the National Institute of Health and World Health Organisation guidelines $[30,31]$. Diabetes mellitus (DM) status was determined based on fasting blood glucose $(\mathrm{FBG}) \geq 7.0 \mathrm{mmol} / \mathrm{L}$ and/or HbAlc $\geq 49 \mathrm{mmol} / \mathrm{mol}$ at the time of study [32]. Time since pancreatitis was defined as number of months since first hospital admission due to acute pancreatitis to the time of blood collection. Recurrence: individuals determined with recurrent acute pancreatitis were admitted with at least one episode of confirmed acute pancreatitis since their first admission with acute pancreatitis to their time of participation in the study. Severity of acute pancreatitis: was defined in accordance with the 2012 Determinant-Based Classification [33, 34].

\section{Statistical analyses}

Statistical analyses were performed using SPSS 23.0 for Mac OSX (IBM Corp., 2015). Mann-Whitney $U$ test and Fisher's exact tests were used to assess differences in baseline characteristics for continuous and categorical variables, respectively. All data were reported as either median and interquartile range (IQR) or frequencies. Having met all statistical assumptions, binary logistic regression was used to investigate the relationship between gut hormones, pancreatic hormones and pro-inflammatory cytokines in Maori versus non-Maori participants. C-peptide was log transformed for the analyses. Extreme data points were omitted to reduce the influence of outliers and to obtain the most robust and conservative output. Each peptide was analyzed as the independent variable in one unadjusted model and four adjusted models. In the unadjusted model, the association between participant's ethnicity and peptide levels was investigated. Model 1 was adjusted for age and sex; model 2 was adjusted for age, sex, smoking, exercise, BMI and DM status; model 3 was adjusted for pancreatitis-related factors, including etiology, recurrence, time since pancreatitis and severity of acute pancreatitis; while model 4 was adjusted for all of the factors mentioned above. All data are reported as $\beta$ coefficients and odds ratio (OR) with corresponding 95\% confidence intervals (CIs). $\mathrm{P}<0.05$ was accepted as statistically significant in all analyses.

\section{Results}

\section{Patient characteristics}

A total of 93 individuals were recruited into the study, of who eight $(8.6 \%)$ were Maori and 85 (91.4\%) were non-Maori. The 
Table 1. Baseline Participant Characteristics

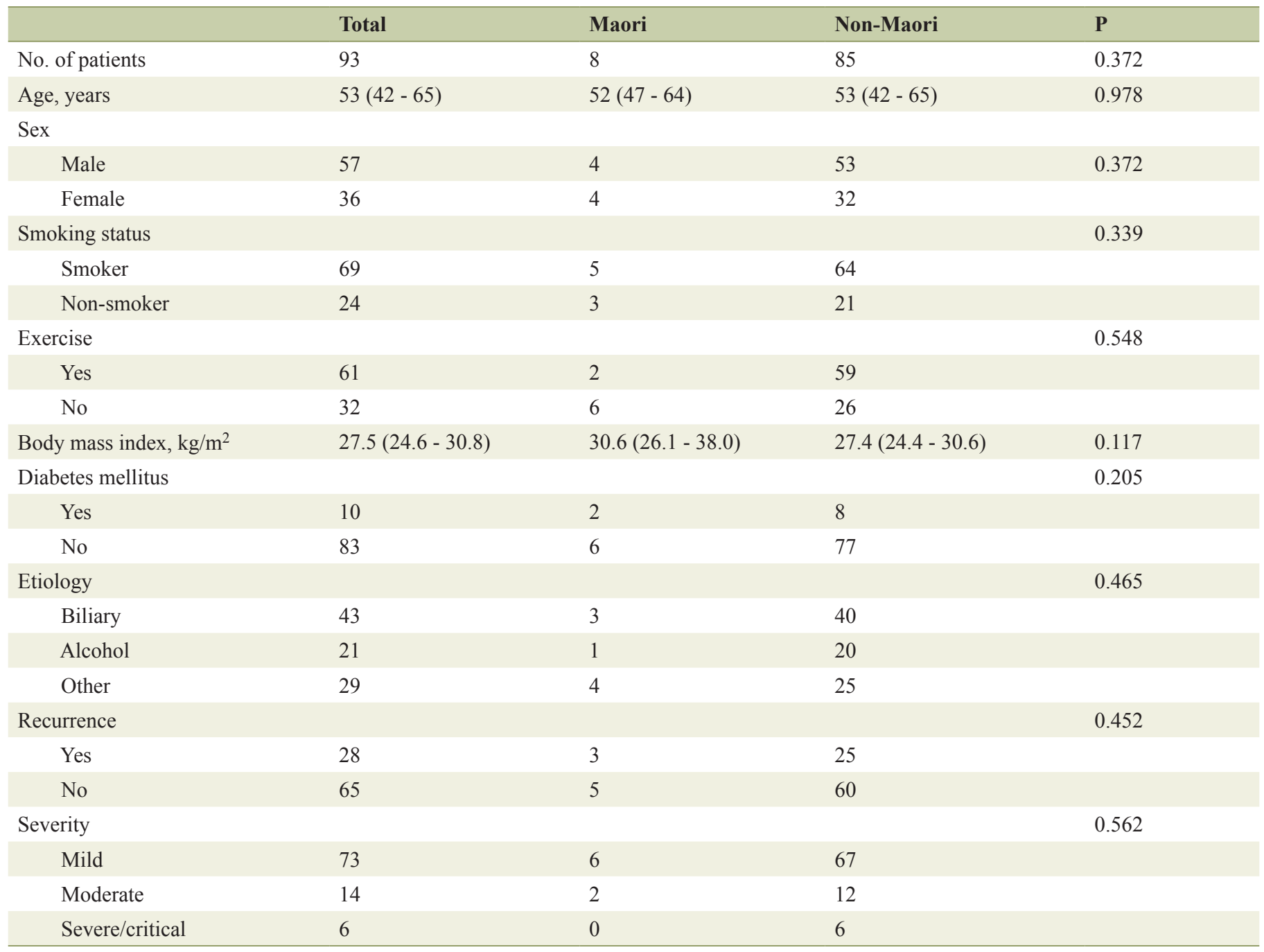

Data presented as median (interquartile range) or count values.

median (IQR) age of the entire cohort was 53 (42 - 65) years and $57(60 \%)$ of all participants were male. The other baseline characteristics for all study participants are shown in Table 1.

\section{Gut hormones}

Ghrelin was significantly higher among Maori participants with a median (IQR) of $17.76(7.21-42.13) \mathrm{ng} / \mathrm{mL}$ and 8.38 $(4.24-14.36) \mathrm{ng} / \mathrm{mL}$ in non-Maori participants $(\mathrm{P}=0.016)$. The comparison of distribution of ghrelin levels between the two groups are illustrated in Figure 1. Ghrelin was significantly higher in Maori participants across all five models with the highest OR (95\% CI; P value) reported in model 4 with an OR of 1.111 (1.012 - 1.219; $\mathrm{P}=0.027)$. Glicentin was significantly higher in Maori participants in four models with the highest OR reported in model 2 with an OR of 1.104 (1.011 - 1.206; P =0.027). Cholecystokinin, gastrin, GIP, GLP-1, GLP-2, PYY, oxyntomodulin and secretin were not found to be significantly associated with ethnicity in any of the five models (Table 2).

\section{Pancreatic hormones}

Pancreatic polypeptide was significantly higher in Maori participants with a median (IQR) of $184.51(63.87$ - 427.04) ng/ $\mathrm{mL}$ and 45.69 (15.91 - 109.26) ng/mL in non-Maori participants $(\mathrm{P}=0.008)$. The comparison of distribution of PP levels between the two groups are illustrated in Figure 2. Pancreatic polypeptide was significantly higher in Maori participants consistently across all five models with the highest OR in model 4 with an OR (95\% CI; P value) of 1.013 (1.002 - 1.025; $\mathrm{P}=0.024)$. Amylin was significantly decreased in Maori participants in two models with the lowest OR in model 4 with an OR of 0.234 (0.059 - 0.937; P =0.040). C-peptide, glucagon, insulin and somatostatin were not found to be significantly associated with ethnicity in any of the five models (Table 3). 


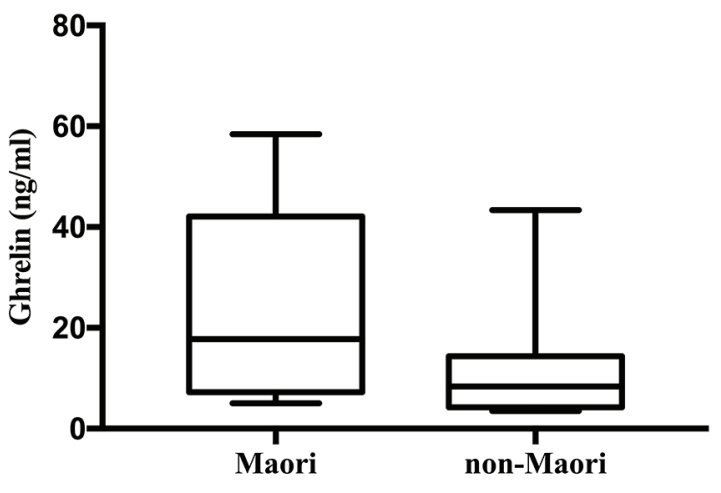

Figure 1. Ghrelin levels in Maori versus non-Maori.

\section{Pro-inflammatory cytokines}

IL-6 was significantly higher in Maori participants with a median (IQR) of $11.21(1.93$ - 50.47) ng/mL and 1.87 (0.26 - 6.72) $\mathrm{ng} / \mathrm{mL}$ in non-Maori participants $(\mathrm{P}=0.013)$. The comparison of distribution of IL-6 levels between the two groups are illustrated in Figure 3. IL-6 was significantly higher in Maori participants consistently across all five models with the highest OR in model 4 with an OR (95\% CI; P value) of 1.256 (1.016 - 1.554; $\mathrm{P}=0.035)$. MCP-1 and TNF $\alpha$ were not found to be significantly associated with ethnicity in any of the five models (Table 4).

\section{Discussion}

This is the first study to investigate a comprehensive panel of gut hormones, pancreatic hormones and pro-inflammatory cytokines in Maori individuals. Multi-level statistical modelling was used to determine differences in the levels of studied hormones and pro-inflammatory cytokines between Maori and non-Maori participants and statistical models were adjusted for demographic, metabolic and pancreatitis-related factors in order to obtain the most robust results. Maori ethnicity was significantly associated (consistently across all statistical models) with elevated levels of ghrelin, PP and IL-6 in both unadjusted and adjusted analyses (controlling for BMI, DM status, pancreatitis-related characteristics and other covariates). These findings provide the first preliminary evidence that Maori individuals may differ to non-Maori individuals in hormone makeup, which may contribute towards understanding the pathogenesis of obesity in this ethnic group.

The first key finding of this study was that Maori participants had significantly higher fasting ghrelin levels. Ghrelin is a 28 amino acid peptide with a N-octanylated serine residue and an endogenous ligand of the growth hormone secretagogue receptor, which stimulates the release of the growth hormone $[35,36]$. Commonly referred to as the "hunger hormone" $[37,38]$, ghrelin is involved in regulating energy consumption across the gut-brain axis by stimulating appetite [36, 39]. Elevated circulating ghrelin is seen in the Panders-Willis syndrome - a genetic condition pre-disposing individuals to obesity and hyperphagia $[40,41]$. Given the orexigenic effect of ghrelin, elevated fasting levels of this hormone in Maori individuals suggests that ghrelin may play an important role in regulating energy balance, whereby increased levels contribute to higher food consumption and increased propensity towards excessive fat storage, leading to obesity.

The second key finding of this study was that Maori participants had significantly elevated PP levels compared to the non-Maori participants. Pancreatic polypeptide is a member of the PP-fold family and is a straight-chain of 36 amino acid peptide [42] secreted primarily by PP cells located in the pancreatic islets of Langerhans [43]. Pancreatic polypeptide secretion is controlled by the vagus nerve, and its secretion is conventionally thought to be stimulated only postprandially [35, 43, 44]. However, a recent study by Arosio et al [45] showed that intravenous administration of ghrelin in healthy subjects resulted in increased fasting levels of PP. Pancreatic polypeptide is also associated with adiposity and has been demonstrated to be a biomarker of abdominal adiposity [46] as well as a biomarker for visceral and intra-hepatocellular fat content in overweight individuals [47]. Pancreatic polypeptide levels are known to differ between ethnicities, where in Pima Indians PP is elevated (both in fasting state and postprandially) compared to Caucasians [48, 49]. Further, a study by Koska et al [20] found that increased levels of fasting PP in Pima Indian males indicate a higher risk of future weight gain. Given these findings, elevated circulating PP levels are indicative of a greater risk of obesity, mechanistically thought to be caused by increased visceral parasympathetic activity [48]. In the present study, fasting PP was significantly higher in Maori (even after controlling for factors such as BMI, DM status and other covariates), which suggests that PP levels may be innately higher in Maori individuals [46, 50]. Further, PP may also be elevated in Maori in response to elevated circulating ghrelin levels reported above [45]. Based on these findings, we hypothesize that increased PP may herald an increased propensity for obesity in Maori individuals.

The third key finding of this study was that Maori participants had significantly elevated IL-6 levels in comparison to non-Maori participants. IL-6 is a multifunctional mediator and a member of the cytokine family [51]. IL-6 is best known for its role in the inflammatory response, and also a key mediator implicated in chronic low-grade inflammation and pathogenesis of metabolic dysregulation [52-57]. Many factors have been demonstrated to alter IL-6 secretion, including hyperglycemia [14], circulating PP levels [15] and presence of metabolic disorders [58-60]. Elevated fasting IL-6 is also associated with both general obesity [61] and abdominal obesity [13, 54], due to the increased secretion of IL-6 from excess adipose tissue [62]. Further, Vozarova et al [63] demonstrated that IL-6 is associated with increased body fat, fat mass and waist circumference in Pima Indians. In our study, we found that fasting IL-6 levels were increased in Maori individuals across all statistical models that controlled for covariates known to influence IL-6 levels (including but not limited to BMI and DM status) [13, $14,61]$. The findings of this study suggest that Maori individuals experience an amplified chronic low-grade inflammatory response compared to non-Maori individuals. However, due to the pluripotent nature of IL-6, the clinical implications of 
Table 2. Gut Hormones in Maori Versus Non-Maori

\begin{tabular}{|c|c|c|c|c|c|c|}
\hline \multirow{2}{*}{ Gut hormones } & \multirow{2}{*}{ Model } & \multirow{2}{*}{ Regression coefficient $(\beta)$} & \multirow{2}{*}{ OR } & \multicolumn{2}{|c|}{$95 \%$ CI } & \multirow{2}{*}{$\mathbf{P}$} \\
\hline & & & & Lower & Upper & \\
\hline \multirow[t]{4}{*}{ Cholecystokinin } & Unadjusted & 0.846 & 2.331 & 0.448 & 12.126 & 0.314 \\
\hline & 1 & 0.836 & 2.308 & 0.446 & 11.943 & 0.319 \\
\hline & 3 & 0.606 & 1.833 & 0.307 & 10.934 & 0.506 \\
\hline & 4 & 0.362 & 1.437 & 0.186 & 11.081 & 0.728 \\
\hline \multirow{3}{*}{ Ghrelin } & 2 & 0.088 & 1.092 & 1.023 & 1.166 & 0.008 \\
\hline & 3 & 0.079 & 1.082 & 1.012 & 1.157 & 0.021 \\
\hline & 4 & 0.105 & 1.111 & 1.012 & 1.219 & 0.027 \\
\hline \multirow[t]{2}{*}{ Gastric inhibitory polypeptide } & Unadjusted & 0.005 & 1.005 & 0.995 & 1.014 & 0.354 \\
\hline & 1 & 0.005 & 1.005 & 0.995 & 1.015 & 0.299 \\
\hline \multirow[t]{5}{*}{ Glicentin } & Unadjusted & 0.077 & 1.080 & 1.017 & 1.148 & 0.013 \\
\hline & 1 & 0.081 & 1.084 & 1.018 & 1.155 & 0.012 \\
\hline & 2 & 0.099 & 1.104 & 1.011 & 1.206 & 0.027 \\
\hline & 3 & 0.076 & 1.079 & 1.009 & 1.153 & 0.027 \\
\hline & 4 & 0.083 & 1.086 & 0.983 & 1.200 & 0.103 \\
\hline \multirow[t]{5}{*}{ Glucagon-like peptide-1 } & Unadjusted & 0.211 & 1.235 & 0.937 & 1.629 & 0.135 \\
\hline & 1 & 0.223 & 1.250 & 0.922 & 1.694 & 0.151 \\
\hline & 2 & 0.221 & 1.247 & 0.894 & 1.740 & 0.193 \\
\hline & 3 & 0.283 & 1.327 & 0.956 & 1.843 & 0.091 \\
\hline & 4 & 0.415 & 1.515 & 0.962 & 2.387 & 0.073 \\
\hline \multirow{3}{*}{ Oxyntomodulin } & 2 & -0.022 & 0.978 & 0.921 & 1.038 & 0.466 \\
\hline & 3 & -0.033 & 0.967 & 0.911 & 1.027 & 0.279 \\
\hline & 4 & -0.042 & 0.959 & 0.895 & 1.028 & 0.238 \\
\hline \multirow[t]{5}{*}{ Peptide YY } & Unadjusted & 0.003 & 1.003 & 0.997 & 1.009 & 0.292 \\
\hline & 1 & 0.004 & 1.004 & 0.998 & 1.010 & 0.226 \\
\hline & 2 & 0.004 & 1.004 & 0.998 & 1.011 & 0.217 \\
\hline & 3 & 0.005 & 1.005 & 0.998 & 1.011 & 0.137 \\
\hline & 4 & 0.006 & 1.006 & 0.999 & 1.013 & 0.111 \\
\hline \multirow[t]{5}{*}{ Secretin } & Unadjusted & 2.841 & 17.132 & 0.243 & 1208.835 & 0.191 \\
\hline & 1 & 2.871 & 17.663 & 0.252 & 1238.300 & 0.185 \\
\hline & 2 & 3.511 & 33.480 & 0.275 & 4071.267 & 0.152 \\
\hline & 3 & 1.286 & 3.618 & 0.031 & 427.932 & 0.597 \\
\hline & 4 & 3.233 & 25.343 & 0.064 & 10080.329 & 0.290 \\
\hline
\end{tabular}

OR: odds ratio; Cl: confidence interval. OR indicate membership to Maori. Model 1 for all gut hormones was adjusted for age and sex. Model 2 for all gut hormones was adjusted for age, sex, smoking, exercise, BMI and diabetes mellitus. Model 3 for all gut hormones was adjusted for etiology, recurrence, time since pancreatitis and severity. Model 4 for all gut hormones was adjusted for age, sex, smoking, exercise, BMI, diabetes mellitus, etiology, recurrence, time since pancreatitis and severity. 


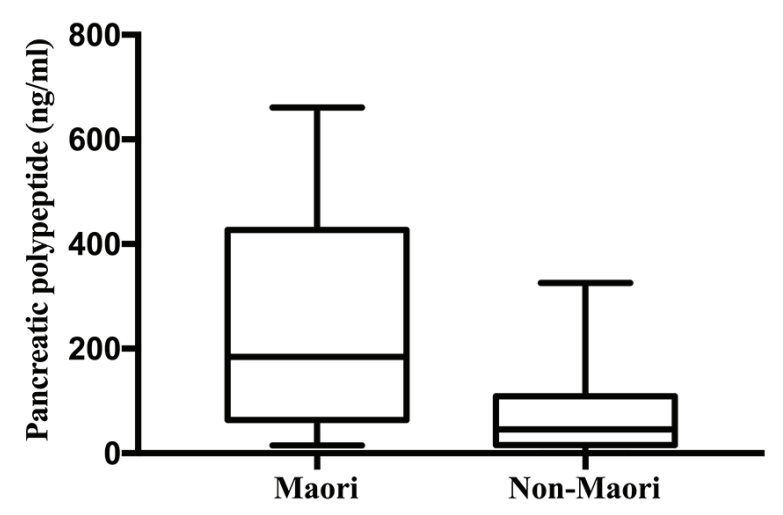

Figure 2. Pancreatic polypeptide levels in Maori versus non-Maori.

Table 3. Pancreatic Hormones in Maori Versus Non-Maori the cross-talk between IL- 6 and obesity in Maori needs to be investigated in future studies. Further, IL- 6 was not controlled for ghrelin or PP levels; therefore, it cannot be ruled out that IL-6 is elevated in response to the increased secretion of these two hormones. Prospective studies are now warranted to understand the interactions of IL- 6 with gut and pancreatic hormones, which may elucidate its function in pathogenesis of obesity in Maori individuals.

There are several limitations to this study. First, given the cross-sectional design, no inferences can be drawn as to whether ghrelin, PP and IL-6 are causes or consequences of obesity in Maori individuals. A prospective longitudinal study is now warranted to determine whether Maori individuals have a higher predisposition to increased circulating levels of certain hormones and pro-inflammatory cytokines. Second, all studied hormones and pro-inflammatory cytokines were measured in fasting state. Given that certain gut and pancreatic hormones

\begin{tabular}{|c|c|c|c|c|c|c|}
\hline \multirow{2}{*}{ Pancreatic hormone } & \multirow{2}{*}{ Model } & \multirow{2}{*}{ Regression coefficient ( $\beta)$} & \multirow{2}{*}{ OR } & \multicolumn{2}{|c|}{$95 \%$ CI } & \multirow{2}{*}{$\mathbf{P}$} \\
\hline & & & & Lower & Upper & \\
\hline \multirow[t]{5}{*}{ Amylin } & Unadjusted & -0.378 & 0.685 & 0.375 & 1.252 & 0.219 \\
\hline & 1 & -0.388 & 0.678 & 0.363 & 1.267 & 0.223 \\
\hline & 2 & -0.934 & 0.393 & 0.157 & 0.985 & 0.046 \\
\hline & 3 & -0.432 & 0.649 & 0.319 & 1.323 & 0.234 \\
\hline & 4 & -1.451 & 0.234 & 0.059 & 0.937 & 0.040 \\
\hline \multirow{4}{*}{ C-peptide } & 1 & -0.595 & 0.551 & 0.063 & 4.799 & 0.590 \\
\hline & 2 & -0.593 & 0.553 & 0.054 & 5.632 & 0.617 \\
\hline & 3 & -0.782 & 0.457 & 0.043 & 4.860 & 0.516 \\
\hline & 4 & -3.209 & 0.040 & 0.001 & 2.327 & 0.121 \\
\hline Glucagon & Unadjusted & -0.001 & 0.999 & 0.983 & 1.016 & 0.900 \\
\hline \multirow[t]{5}{*}{ Insulin } & Unadjusted & 0.006 & 1.006 & 0.996 & 1.017 & 0.248 \\
\hline & 1 & 0.006 & 1.006 & 0.996 & 1.016 & 0.231 \\
\hline & 2 & 0.004 & 1.004 & 0.989 & 1.020 & 0.619 \\
\hline & 3 & 0.010 & 1.011 & 0.993 & 1.029 & 0.246 \\
\hline & 4 & 0.006 & 1.006 & 0.985 & 1.027 & 0.593 \\
\hline \multirow[t]{5}{*}{ Pancreatic polypeptide } & Unadjusted & 0.011 & 1.011 & 1.003 & 1.018 & 0.004 \\
\hline & 1 & 0.011 & 1.011 & 1.004 & 1.018 & 0.003 \\
\hline & 2 & 0.011 & 1.011 & 1.003 & 1.019 & 0.007 \\
\hline & 3 & 0.011 & 1.011 & 1.003 & 1.019 & 0.008 \\
\hline & 4 & 0.013 & 1.013 & 1.002 & 1.025 & 0.024 \\
\hline
\end{tabular}

OR: odds ratio; $\mathrm{Cl}$ : confidence interval. OR indicate for membership to Maori. Model 1 for all pancreatic hormones was adjusted for age and sex. Model 2 for all pancreatic hormones was adjusted for age, sex, smoking, exercise, BMI and diabetes mellitus. Model 3 for all pancreatic hormones was adjusted for etiology, recurrence, time since pancreatitis and severity. Model 4 for all pancreatic hormones was adjusted for age, sex, smoking, exercise, BMI, diabetes mellitus, etiology, recurrence, time since pancreatitis and severity. C-peptide values were log $_{10}$ transformed. 


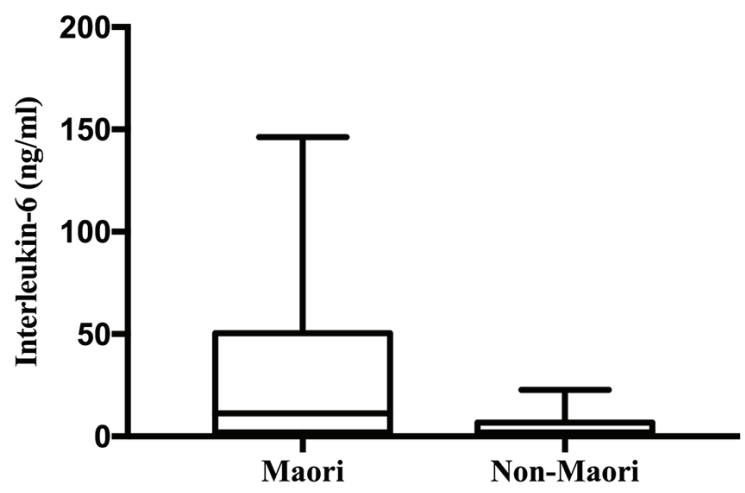

Figure 3. Interleukin-6 levels in Maori versus non-Maori.

are secreted postprandially, future studies should use mixed meal test [64] to determine whether circulating levels of the studied hormones are altered in Maori individuals. Nonetheless, the present study allowed us to rule out the effect of nutrition, suggesting that other factors are also responsible for the altered hormonal secretion [65-67]. Third, this study did not investigate genetic variations between ethnicities; therefore, congenital differences in hormone secretion related to ethnicity cannot be ruled out. Future studies are warranted to determine if differences in hormone and pro-inflammatory cytokine secretion stem from genetic variations that may occur between ethnicities. Fourth, all participants in this study had a history of an attack of acute pancreatitis. However, the course of disease was mild to moderate in the majority of study participants and blood samples were collected, on average, in nearly 2 years since an attack. Further, the multi-level statistical modelling, including pancreatitis-related factors, ensured the most robust and conservative output [68]. Last, the study included a limited number of Maori individuals due to the post-hoc nature of the analysis. Hence, the findings of this study should be treated as preliminary to justify a larger purposely-designed prospective study that specifically investigates profile of gut hormones, pancreatic hormones and pro-inflammatory cytokines in Maori, as well as its relation to obesity and DM.

In conclusion, this study suggests that Maori individuals may have significantly altered levels of ghrelin, PP and IL-6, even after controlling for BMI, DM status and other covariates. Further research is needed to investigate clinical and public health implications of these findings. Identifying pathophysiological differences in the development of obesity may contribute towards improving health outcomes in this ethnic group.

\section{Acknowledgments}

This study was part of the Clinical and epidemiOlogical inveStigations in Metabolism, nutritiOn, and pancreatic diseaseS (COSMOS) program. COSMOS is supported in party by the Health Research Council of New Zealand (grant 15/035 to Associate Professor Max Petrov), which played no role in the study design, collection, analysis, interpretation of data or writing of the manuscript.

Table 4. Pro-Inflammatory Cytokines in Maori Versus Non-Maori

\begin{tabular}{|c|c|c|c|c|c|c|}
\hline \multirow{2}{*}{ Cytokies } & \multirow{2}{*}{ Model } & \multirow{2}{*}{ Regression coefficient $(\beta)$} & \multirow{2}{*}{ OR } & \multicolumn{2}{|c|}{$95 \% \mathrm{CI}$} & \multirow{2}{*}{$\mathbf{P}$} \\
\hline & & & & Lower & Upper & \\
\hline \multirow[t]{3}{*}{ Interleukin-6 } & Unadjusted & 0.110 & 1.117 & 1.012 & 1.233 & 0.029 \\
\hline & 2 & 0.197 & 1.218 & 1.031 & 1.438 & 0.020 \\
\hline & 3 & 0.208 & 1.231 & 1.046 & 1.448 & 0.012 \\
\hline \multirow[t]{5}{*}{ Monocyte chemoattractant protein-1 } & Unadjusted & 0.005 & 1.005 & 0.997 & 1.014 & 0.227 \\
\hline & 1 & 0.007 & 1.007 & 0.998 & 1.017 & 0.134 \\
\hline & 2 & 0.008 & 1.008 & 0.998 & 1.019 & 0.117 \\
\hline & 3 & 0.005 & 1.005 & 0.997 & 1.014 & 0.223 \\
\hline & 4 & 0.012 & 1.012 & 0.999 & 1.026 & 0.070 \\
\hline \multirow{2}{*}{ Tumour necrosis factor- $\alpha$} & 3 & 0.100 & 1.105 & 0.936 & 1.304 & 0.239 \\
\hline & 4 & 0.186 & 1.204 & 0.963 & 1.506 & 0.103 \\
\hline
\end{tabular}

OR: odds ratio; Cl: confidence interval. OR indicate membership to Maori. Model 1 for all cytokines was adjusted for age and sex. Model 2 for all cytokines was adjusted for age, sex, smoking, exercise, BMI and diabetes mellitus. Model 3 for all cytokines was adjusted for etiology, recurrence, time since pancreatitis and severity. Model 4 for all cytokines was adjusted for age, sex, smoking, exercise, BMl, diabetes mellitus, etiology, recurrence, time since pancreatitis and severity. 


\section{Conflict of Interest}

Aya Cervantes, Ruma G. Singh, Sayali A. Pendharkar, Sakina H. Bharmal and Maxim S. Petrov declare that they have no conflict of interest.

\section{Ethical Statement}

All procedures followed were in accordance with the national and international ethical standards of the Health and Disability Ethics Committee and of the Helsinki Declaration of 1975, as revised in 2000. Informed consent was obtained by all subjects for being included in the study.

\section{References}

1. World Health Organisation. WHO | Obesity and overweight. WHO [Internet]. 2017 [cited 2017 Jun 29]; Available from: http:/www.who.int/mediacentre/factsheets/ fs311/en/.

2. Ministry of Health. Obesity statistics [Internet]. Ministry of Health. 2017 [cited 2017 Jun 15]. Available from: http://www.health.govt.nz/nz-health-statistics/health-statistics-and-data-sets/obesity-statistics.

3. Ellison-Loschmann L, Pearce N. Improving access to health care among New Zealand's Maori population. Am J Public Health. 2006;96(4):612-617.

4. Pendharkar SA, Mathew J, Zhao J, Windsor JA, Exeter DJ, Petrov MS. Ethnic and geographic variations in the incidence of pancreatitis and post-pancreatitis diabetes mellitus in New Zealand: a nationwide population-based study. N Z Med J. 2017;130(1450):55-68.

5. Knowler WC, Pettitt DJ, Saad MF, Bennett PH. Diabetes mellitus in the Pima Indians: incidence, risk factors and pathogenesis. Diabetes Metab Rev. 1990;6(1):1-27.

6. Lindsay RS, Cook V, Hanson RL, Salbe AD, Tataranni A, Knowler WC. Early excess weight gain of children in the Pima Indian population. Pediatrics. 2002;109(2):E33.

7. Anand SS, Yusuf S, Jacobs R, Davis AD, Yi Q, Gerstein H, Montague PA, et al. Risk factors, atherosclerosis, and cardiovascular disease among Aboriginal people in Canada: the Study of Health Assessment and Risk Evaluation in Aboriginal Peoples (SHARE-AP). Lancet. 2001;358(9288):1147-1153.

8. Spence ND. Does Social Context Matter? Income Inequality, Racialized Identity, and Health Among Canada's Aboriginal Peoples Using a Multilevel Approach. J Racial Ethn Health Disparities. 2016;3(1):21-34.

9. Australian Bureau of Statistics. Chapter - Overweight and obesity (BMI). [cited 2017 Jun 29]; Available from: http://www.abs.gov.au/ausstats/abs@.nsf/Lookup/4727.0 .55.001Chapter3102012-13.

10. Ho CS, Tsai AC. Prevalence of overweight and obesity and its associated factors in aboriginal Taiwanese: findings from the 2001 National Health Interview Survey in Taiwan. Asia Pac J Clin Nutr. 2007;16(3):572-579.
11. Pendharkar SA, Asrani VM, Murphy R, Cutfield R, Windsor JA, Petrov MS. The Role of Gut-brain Axis in Regulating Glucose Metabolism After Acute Pancreatitis. Clin Transl Gastroenterol. 2017;8(1):e210.

12. Adamska E, Ostrowska L, Gorska M, Kretowski A. The role of gastrointestinal hormones in the pathogenesis of obesity and type 2 diabetes. Prz Gastroenterol. 2014;9(2):69-76.

13. Singh RG, Pendharkar SA, Gillies NA, Miranda-Soberanis V, Plank LD, Petrov MS. Associations between circulating levels of adipocytokines and abdominal adiposity in patients after acute pancreatitis. Clin Exp Med. 2017;17(4):477-487.

14. Gillies N, Pendharkar SA, Asrani VM, Mathew J, Windsor JA, Petrov MS. Interleukin-6 is associated with chronic hyperglycemia and insulin resistance in patients after acute pancreatitis. Pancreatology. 2016;16(5):748-755.

15. Pendharkar SA, Singh RG, Petrov MS. Cross-talk between innate cytokines and the pancreatic polypeptide family in acute pancreatitis. Cytokine. 2017;90:161-168.

16. Gillies NA, Pendharkar SA, Singh RG, Windsor JA, Bhatia M, Petrov MS. Fasting levels of insulin and amylin after acute pancreatitis are associated with pro-inflammatory cytokines. Arch Physiol Biochem. 2017;123(4):238248.

17. Courtney-Long EA, Romano SD, Carroll DD, Fox MH. Socioeconomic factors at the intersection of race and ethnicity influencing health risks for people with disabilities. J Racial Ethn Health Disparities. 2017;4(2):213-222.

18. Vasudevan DA, Northrup TF, Mandayam S, Bamidele OO, Stotts AL. Impact of Physician Training on Diagnosis and Counseling of Overweight and Obese Asian Patients. J Racial Ethn Health Disparities. 2017;4(3):322328.

19. Hu H, Odedina FT, Reams RR, Lissaker CT, Xu X. Racial Differences in Age-Related Variations of Testosterone Levels Among US Males: Potential Implications for Prostate Cancer and Personalized Medication. J Racial Ethn Health Disparities. 2015;2(1):69-76.

20. Koska J, DelParigi A, de Courten B, Weyer C, Tataranni PA. Pancreatic polypeptide is involved in the regulation of body weight in pima Indian male subjects. Diabetes. 2004;53(12):3091-3096.

21. Karim MA, Wang X, Hale TC, Elbein SC. Insulin Promoter Factor 1 variation is associated with type 2 diabetes in African Americans. BMC Med Genet. 2005;6:37.

22. Bi M, Kao WH, Boerwinkle E, Hoogeveen RC, Rasmussen-Torvik LJ, Astor BC, North KE, et al. Association of rs780094 in GCKR with metabolic traits and incident diabetes and cardiovascular disease: the ARIC Study. PLoS One. 2010;5(7):e11690.

23. Hegele RA, Ramdath DD, Ban MR, Carruthers MN, Carrington $\mathrm{CV}$, Cao $\mathrm{H}$. Polymorphisms in PNLIP, encoding pancreatic lipase, and associations with metabolic traits. J Hum Genet. 2001;46(6):320-324.

24. Kimm SY, Glynn NW, Aston CE, Damcott CM, Poehlman ET, Daniels SR, Ferrell RE. Racial differences in the relation between uncoupling protein genes and resting energy expenditure. Am J Clin Nutr. 2002;75(4):714-719. 
25. Harris MI, Cowie CC, Gu K, Francis ME, Flegal K, Eberhardt MS. Higher fasting insulin but lower fasting Cpeptide levels in African Americans in the US population. Diabetes Metab Res Rev. 2002;18(2):149-155.

26. Maravi Poma E, Zubia Olascoaga F, Petrov MS, Navarro Soto S, Laplaza Santos C, Morales Alava F, Darnell Martin A, et al. SEMICYUC 2012. Recommendations for intensive care management of acute pancreatitis. Med Intensiva. 2013;37(3):163-179.

27. Singh RG, Pendharkar SA, Plank LD, Petrov MS. Role of human lipocalin proteins in abdominal obesity after acute pancreatitis. Peptides. 2017;91:1-7.

28. Pendharkar SA, Asrani VM, Xiao AY, Yoon HD, Murphy R, Windsor JA, Petrov MS. Relationship between pancreatic hormones and glucose metabolism: A cross-sectional study in patients after acute pancreatitis. Am J Physiol Gastrointest Liver Physiol. 2016;311(1):G50-58.

29. Gillies NA, Pendharkar SA, Singh RG, Asrani VM, Petrov MS. Lipid metabolism in patients with chronic hyperglycemia after an episode of acute pancreatitis. Diabetes Metab Syndr. 2017;11(Suppl 1):S233-S241.

30. Janssen I, Katzmarzyk PT, Ross R. Body mass index, waist circumference, and health risk: evidence in support of current National Institutes of Health guidelines. Arch Intern Med. 2002;162(18):2074-2079.

31. Obesity: preventing and managing the global epidemic. Report of a WHO consultation. World Health Organ Tech Rep Ser. 2000;894:i-xii, 1-253.

32. American Diabetes A. Diagnosis and classification of diabetes mellitus. Diabetes Care. 2010;32(Suppl 1):S62-69.

33. Petrov MS, Windsor JA. Conceptual framework for classifying the severity of acute pancreatitis. Clin Res Hepatol Gastroenterol. 2012;36(4):341-344.

34. Dellinger EP, Forsmark CE, Layer P, Levy P, MaraviPoma E, Petrov MS, Shimosegawa T, et al. Determinantbased classification of acute pancreatitis severity: an international multidisciplinary consultation. Ann Surg. 2012;256(6):875-880.

35. Kojima M, Kangawa K. Ghrelin: structure and function. Physiol Rev. 2005;85(2):495-522.

36. Churm R, Davies JS, Stephens JW, Prior SL. Ghrelin function in human obesity and type 2 diabetes: a concise review. Obes Rev. 2017;18(2):140-148.

37. Seim I, El-Salhy M, Hausken T, Gundersen D, Chopin L. Ghrelin and the brain-gut axis as a pharmacological target for appetite control. Curr Pharm Des. 2012;18(6):768775.

38. Broglio F, Arvat E, Benso A, Gottero C, Muccioli G, Papotti M, van der Lely AJ, et al. Ghrelin, a natural GH secretagogue produced by the stomach, induces hyperglycemia and reduces insulin secretion in humans. J Clin Endocrinol Metab. 2001;86(10):5083-5086.

39. Sharifi F, Yamini M, Esmaeilzadeh A, Mousavinasab N, Shajari Z. Acylated ghrelin and leptin concentrations in patients with type 2 diabetes mellitus, people with prediabetes and first degree relatives of patients with diabetes, a comparative study. J Diabetes Metab Disord. 2013;12(1):51.

40. DelParigi A, Tschop M, Heiman ML, Salbe AD, Vozarova
B, Sell SM, Bunt JC, et al. High circulating ghrelin: a potential cause for hyperphagia and obesity in prader-willi syndrome. J Clin Endocrinol Metab. 2002;87(12):54615464.

41. Haqq AM, Farooqi IS, O'Rahilly S, Stadler DD, Rosenfeld RG, Pratt KL, LaFranchi SH, et al. Serum ghrelin levels are inversely correlated with body mass index, age, and insulin concentrations in normal children and are markedly increased in Prader-Willi syndrome. J Clin Endocrinol Metab. 2003;88(1):174-178.

42. Pendharkar SA, Singh RG, Chand SK, Cervantes A, Petrov MS. Pro-inflammatory cytokines after an episode of acute pancreatitis: associations with fasting gut hormone profile. Inflamm Res. 2018;67(4):339-350.

43. Kojima S, Ueno N, Asakawa A, Sagiyama K, Naruo $\mathrm{T}$, Mizuno S, Inui A. A role for pancreatic polypeptide in feeding and body weight regulation. Peptides. 2007;28(2):459-463.

44. Glaser B, Vinik AI, Sive AA, Floyd JC, Jr. Plasma human pancreatic polypeptide responses to administered secretin: effects of surgical vagotomy, cholinergic blockade, and chronic pancreatitis. J Clin Endocrinol Metab. 1980;50(6):1094-1099.

45. Arosio M, Ronchi CL, Gebbia C, Cappiello V, Beck-Peccoz P, Peracchi M. Stimulatory effects of ghrelin on circulating somatostatin and pancreatic polypeptide levels. J Clin Endocrinol Metab. 2003;88(2):701-704.

46. Sam AH, Sleeth ML, Thomas EL, Ismail NA, Mat Daud N, Chambers E, Shojaee-Moradie F, et al. Circulating pancreatic polypeptide concentrations predict visceral and liver fat content. J Clin Endocrinol Metab. 2015;100(3):1048-1052.

47. Hamaguchi M, Kojima T, Takeda N, Nagata C, Takeda J, Sarui H, Kawahito Y, et al. Nonalcoholic fatty liver disease is a novel predictor of cardiovascular disease. World J Gastroenterol. 2007;13(10):1579-1584.

48. Weyer C, Salbe AD, Lindsay RS, Pratley RE, Bogardus C, Tataranni PA. Exaggerated pancreatic polypeptide secretion in Pima Indians: can an increased parasympathetic drive to the pancreas contribute to hyperinsulinemia, obesity, and diabetes in humans? Metabolism. 2001;50(2):223-230.

49. Gingerich RL, Nagulesparan M, Bennion L, Dye ES, Bauman WA. Pancreatic polypeptide in Pima Indians: the influence of obesity and diabetes. Metabolism. 1985;34(1):25-29.

50. Glaser B, Zoghlin G, Pienta K, Vinik AI. Pancreatic polypeptide response to secretin in obesity: effects of glucose intolerance. Horm Metab Res. 1988;20(5):288-292.

51. Pal M, Febbraio MA, Whitham M. From cytokine to myokine: the emerging role of interleukin-6 in metabolic regulation. Immunol Cell Biol. 2014;92(4):331-339.

52. Srikanthan K, Feyh A, Visweshwar H, Shapiro JI, Sodhi K. Systematic review of metabolic syndrome biomarkers: a panel for early detection, management, and risk stratification in the west Virginian population. Int J Med Sci. 2016;13(1):25-38.

53. Pendharkar SA, Singh RG, Petrov MS. Pro-inflammatory cytokine-induced lipolysis after an episode of acute pan- 
creatitis. Arch Physiol Biochem. 2017; [Epub ahead of print].

54. Singh RG, Pendharkar SA, Cervantes A, Cho J, MirandaSoberanis V, Petrov MS. Abdominal obesity and insulin resistance after an episode of acute pancreatitis. Dig Liver Dis. 2018; [Epub ahead of print].

55. Chand SK, Singh RG, Pendharkar SA, Petrov MS. Iron: a strong element in the pathogenesis of chronic hyperglycaemia after acute pancreatitis. Biol Trace Elem Res. 2018;183(1):71-79.

56. Petrov MS. Diabetes of the exocrine pancreas: American Diabetes Association-compliant lexicon. Pancreatology. 2017;17(4):523-526.

57. Chand SK, Singh RG, Pendharkar SA, Bharmal SH, Petrov MS. Interplay between innate immunity and iron metabolism after acute pancreatitis. Cytokine. 2018;103:90-98.

58. Petrov MS. Therapeutic implications of oxidative stress in acute and chronic pancreatitis. Curr Opin Clin Nutr Metab Care. 2010;13(5):562-568.

59. Pradhan AD, Manson JE, Rifai N, Buring JE, Ridker PM. C-reactive protein, interleukin 6, and risk of developing type 2 diabetes mellitus. JAMA. 2001;286(3):327-334.

60. Weiss TW, Arnesen H, Seljeflot I. Components of the interleukin- 6 transsignalling system are associated with the metabolic syndrome, endothelial dysfunction and arterial stiffness. Metabolism. 2013;62(7):1008-1013.

61. Kern PA, Ranganathan S, Li C, Wood L, Ranganathan G. Adipose tissue tumor necrosis factor and interleukin-6 expression in human obesity and insulin resistance.
Am J Physiol Endocrinol Metab. 2001;280(5):E745-751.

62. Roytblat L, Rachinsky M, Fisher A, Greemberg L, Shapira Y, Douvdevani A, Gelman S. Raised interleukin-6 levels in obese patients. Obes Res. 2000;8(9):673-675.

63. Vozarova B, Weyer C, Hanson K, Tataranni PA, Bogardus C, Pratley RE. Circulating interleukin-6 in relation to adiposity, insulin action, and insulin secretion. Obes Res. 2001;9(7):414-417.

64. Dalla Man C, Campioni M, Polonsky KS, Basu R, Rizza RA, Toffolo G, Cobelli C. Two-hour seven-sample oral glucose tolerance test and meal protocol: minimal model assessment of beta-cell responsivity and insulin sensitivity in nondiabetic individuals. Diabetes. 2005;54(11):32653273.

65. Jivanji CJ, Asrani VM, Windsor JA, Petrov MS. Newonset diabetes after acute and critical illness: a systematic review. Mayo Clin Proc. 2017;92(5):762-773.

66. Singh RG, Yoon HD, Wu LM, Lu J, Plank LD, Petrov MS. Ectopic fat accumulation in the pancreas and its clinical relevance: A systematic review, meta-analysis, and meta-regression. Metabolism. 2017;69:1-13.

67. Singh RG, Yoon HD, Poppitt SD, Plank LD, Petrov MS. Ectopic fat accumulation in the pancreas and its biomarkers: A systematic review and meta-analysis. Diabetes Metab Res Rev. 2017;33(8):e2918.

68. Xiao AY, Tan ML, Wu LM, Asrani VM, Windsor JA, Yadav D, Petrov MS. Global incidence and mortality of pancreatic diseases: a systematic review, meta-analysis, and meta-regression of population-based cohort studies. Lancet Gastroenterol Hepatol. 2016;1(1):45-55. 